\title{
Immunolocalisation studies on six matrix metalloproteinases and their inhibitors, TIMP-1 and TIMP-2, in synovia from patients with osteo- and rheumatoid arthritis
}

\author{
R M Hembry, M R Bagga, J J Reynolds, D L Hamblen
}

\begin{abstract}
Objective-To assess the likely importance of matrix metalloproteinases (MMPs) and their inhibitors (TIMPs) in the arthritic process.

Methods-Synovial samples from seven joints with rheumatoid arthritis and three osteoarthritic joints were analysed by indirect immunofluorescence microscopy. Using specific human antisera, we documented the frequencies and distributions of collagenase, stromelysins 1 and 2, matrilysin, gelatinases $A$ and $B$, TIMP-1, and TIMP-2.
\end{abstract}

Results-Stromelysin 1 was found in all synovia, bound to extracellular matrix, within cells, or both, indicating stromelysin synthesis. Matrilysin was present in only one active inflammatory synovium, and focal synthesis of collagenase and gelatinase $A$ was seen in four synovia. Stromelysin 2 and TIMP-2 were not observed, but TIMP-1 synthesis was seen in five synovia, and in two active synovia the distribution of TIMP-1 positive cells was more widespread than that of MMPs.

Conclusions-The presence of stromelysin 1 in all synovia clearly implicates this enzyme in joint damage. Collagenase, gelatinase $A$ and matrilysin may also have a role in rheumatoid arthritis, but are not significant in osteoarthritis. However, marked regional variations were found in the synthesis of these MMPs, indicating not only that these diseases are episodic but that control of enzyme synthesis is focal. Only TIMP-1 may be considered an inhibitory factor.

(Ann Rheum Dis 1995; 54: 25-32)

Progressive degradation of the extracellular matrix of connective tissues and destruction of articular cartilage, intra-articular ligaments, tendons, and subchondral bone are major features of the arthritides, leading to disfigurement and permanent loss of function. ${ }^{12}$ Although proteinases of all mechanistic classes have the potential to degrade individual connective tissue macromolecules in vitro, ${ }^{3}$ the current view is that the initial step in matrix degradation is often an extracellular proteolytic process involving matrix metalloproteinases (MMPs). ${ }^{4}$ MMPs are a family of metaldependent proteinases, which are active at neutral $\mathrm{pH}$ and secreted by mesenchymal and haemopoietic cells as proenzyme forms requiring extracellular activation. Their activities are further regulated by secreted inhibitors, the tissue inhibitors of metalloproteinases (TIMPs). The MMP family can be divided into subgroups, three of which contain multiple gene products. The collagenases specifically cleave interstitial collagens types I, II, and III at a single locus; gelatinases (type IV collagenases) cleave denatured collagens and type IV collagen; while the stromelysins are more general proteinases, cleaving proteoglycan core protein, fibronectin and type IV collagen. In addition, a truncated MMP, matrilysin has a substrate specificity similar to that of the stromelysins. Together, these enzymes have the ability to degrade all the macromolecular components of connective tissues.

There is considerable evidence that connective tissues removed from patients with rheumatoid arthritis secrete greater concentrations of MMPs and their inhibitors into culture media than normal tissues. ${ }^{5-8}$ Cultures of adherent cells derived from rheumatoid synovia secreted collagenase into the culture media $^{9}$ and collagenase was detected within such cells ${ }^{10}$ and at sites of cartilage erosion in rheumatoid joints by immunolocalisation. ${ }^{11}$ Stromelysin $1^{12-15}$ and collagenase ${ }^{16}$ have been demonstrated by immunolocalisation in lining cells of synovia and also mRNA for these proteins was detected by in situ hybridisation. ${ }^{14}{ }^{17-21}$ The last studies also identified collagenase and stromelysin mRNA in osteoarthritic synovium in smaller concentrations than in rheumatoid synovium. Primary rheumatoid synovial fibroblasts expressed high levels of stromelysin $1 \mathrm{mRNA}$ but only small amounts of stromelysin 2 mRNA. ${ }^{22}$ MMPs have also been measured in rheumatoid synovial fluids ${ }^{21} 23-25$ and synovial fluids from osteoarthritic knee joints. ${ }^{21} 2526$ TIMP-1 has been detected in lining cells of rheumatoid synovia by immunolocalisation ${ }^{16}$ and in situ hybridisation, ${ }^{18} 20$ and measured in rheumatoid synovial fluids ${ }^{25} 27$ and synovial fluids from osteoarthritic knee joints. ${ }^{25} 26$

Correspondence to: Dr Hembry

Accepted for publication 11 August 1994 
Although the presence of collagenase, stromelysin and TIMP-1 have been well documented, other MMPs may also contribute to a predominance, either overall or focal, of proteinases over inhibitors, which could result in the breakdown of joint tissues in the arthritides. In this paper we have analysed synovia from seven joints with inflammatory arthritis and three osteoarthritic joints by indirect immunofluorescence microscopy to document the frequencies and distributions of six MMPs (collagenase, stromelysins 1 and 2, gelatinases $\mathrm{A}$ and $\mathrm{B}$, matrilysin) and TIMP-1 and TIMP-2, in order to assess the likely importance of each in the arthritic process.

\section{Materials and methods}

TISSUES

Synovial samples were removed from 10 patients (table 1). Seven of these patients had a diagnosis of rheumatoid arthritis, seropositive rheumatoid arthritis was present in five, and the other two were seronegative but otherwise satisfied the ARA criteria for rheumatoid arthritis. Three of the five patients with seropositive disease (patients 2, 3 and 4) were in an early proliferative phase of their disease showing only minimal damage to the articular cartilage, and were therefore managed by surgical synovectomy. The remaining two patients ( 1 and 5 ) had disease at a more advanced stage, with major destruction of both bone and articular cartilage leading to established secondary osteoarthritic changes. In these the surgical management was by joint debridement or arthroplasty and there was only minimal macroscopic evidence of increased vascularity and synovial hypertrophy. The two patients with atypical seronegative rheumatoid arthritis (patients 6 and 7) both showed advanced joint destruction, although this was still associated with marked proliferative synovial activity. The duration of the inflammatory arthritis varied from two to 24 years, but all patients had received prolonged drug treatment with non-steroidal antiinflammatory agents and some second-line therapy, such as sulphasalazine or gold salts. Only one patient (patient 6) with atypical seronegative arthritis had been taking systemic steroids for several months before removal of

Table 1 Details of patients studied

\begin{tabular}{|c|c|c|c|c|c|c|}
\hline Patient & Sex & $\begin{array}{l}\text { Age } \\
(y r)\end{array}$ & Diagnosis & foint & $\begin{array}{l}\text { Disease } \\
\text { duration (yr) }\end{array}$ & Operation \\
\hline 1 & $\mathrm{~F}$ & 62 & RA (secondary OA) & Elbow & 7 & $\begin{array}{l}\text { Synovectomy } \\
\text { and joint } \\
\text { debridement }\end{array}$ \\
\hline 2 & $\mathbf{M}$ & 69 & RA (active) & Knee & 3 & Synovectomy \\
\hline 3 & $\mathrm{~F}$ & 30 & RA (active) & Knee & 2 & Synovectomy \\
\hline 4 & $\mathrm{~F}$ & 26 & RA (active) & Knee & 11 & Synovectomy \\
\hline 5 & $\mathrm{~F}$ & 51 & $\mathrm{RA}$ (secondary OA) & Knee & 13 & Arthroplasty \\
\hline 6 & $\mathrm{~F}$ & 87 & $\begin{array}{l}\text { Seronegative } \\
\text { rheumatoid arthritis }\end{array}$ & Shoulder & 2 & $\begin{array}{l}\text { Synovectomy } \\
\text { and joint } \\
\text { debridement }\end{array}$ \\
\hline 7 & $\mathrm{~F}$ & 65 & $\begin{array}{l}\text { Seronegative } \\
\text { rheumatoid arthritis }\end{array}$ & Wrist & 24 & $\begin{array}{l}\text { Silastic } \\
\text { arthroplasty }\end{array}$ \\
\hline 8 & $\mathrm{~F}$ & 68 & OA & Knee & 4 & Arthroplasty \\
\hline 9 & $\mathbf{F}$ & 67 & OA & Knee & 20 & Arthroplasty \\
\hline 10 & $\mathbf{M}$ & 60 & OA & Hip & 3 & Arthroplasty \\
\hline
\end{tabular}

RA = Rheumatoid arthritis; $O A=$ osteoarthritis the synovial specimen. All joints in patients with rheumatoid arthritis had received one or more local steroid injections, with the exception of the elbow in patient 1 and the wrist in patient 7 .

In the three patients with osteoarthritis, synovial specimens were removed at the time of surgery for replacement arthroplasty of the joint. In one of these (patient 8) there was macroscopic and microscopic evidence of a pyrophosphate arthropathy (pseudogout), with areas of stippled calcification in all the articular tissues in addition to marked synovial proliferation.

In the laboratory, small pieces were cut from each synovial sample and cultured for $6 \mathrm{~h}$ in Dulbecco's Modified Eagle's Medium with $10 \%$ fetal bovine serum and $5 \mu \mathrm{mol} / 1$ monensin (Sigma) in an atmosphere of 5\% carbon dioxide in air. They were then frozen in liquid nitrogen. A piece adjacent to each cultured sample was also taken and was frozen ex vivo.

\section{ANTIBODIES}

Specific polyclonal antibodies to human gelatinase $\mathrm{A},{ }^{28}$ pig gelatinase $\mathrm{B}$ (which cross reacts with human gelatinase $B$ but not human gelatinase $\mathrm{A}^{29}$ ), human stromelysin (which reacts strongly with stromelysin 1 and weakly with stromelysin $2^{30}$ ), human TIMP- $1^{31}$ and TIMP $-2^{32}$ were raised in sheep. The characterisation of these antisera including species specificity, Western blots, inhibition curves and immunoabsorption experiments with purified antigen are detailed in the references cited. Human interstititial collagenase was purified according to the method of Whitham et $a l,{ }^{33}$ injected into a sheep and the resulting antiserum characterised by Western blotting, inhibition and immunolocalisation as reported above for the other antisera. The antiserum does not cross react with human neutrophil collagenase. Human recombinant promatrilysin was purified, ${ }^{34}$ injected into a sheep, and the antiserum obtained characterised by Western blotting, and by immunolocalisation on NSO mouse myeloma cells transfected with matrilysin. ${ }^{34}$ It was shown to be negative on immunolocalisation of NSO mouse myeloma cells transfected with human stromelysin $1,{ }^{34}$ human stromelysin $2,{ }^{35}$ human collagenase ${ }^{35}$ or human gelatinase A. ${ }^{36}$ Antisera to human stromelysin 2 were raised in rabbits and sheep by injecting either $1 \mathrm{mg}$ or $2 \mathrm{mg}$, respectively, of the peptide VPTKSVPSGSEMPAKC (residues 257-272 in the proenzyme) conjugated to tuberculin purified protein derivative and emulsified in incomplete Freund's adjuvant. Booster injections of 0.5 or $1.0 \mathrm{mg}$, respectively, were given at three-weekly intervals and blood removed 10 days after each injection. Immunoglobulins (IgGs) were prepared from the bleeds with the highest titres. Specificities were determined by Western blotting and immunolocalisation on NSO mouse myeloma cells transfected with stromelysin $2 . .^{35}$ The antisera did not cross 
react with stromelysin 1 , either on Western blotting with purified antigen or on immunolocalisation of NSO mouse myeloma cells transfected with stromelysin $1 .^{34}$ Pooled normal sheep serum (NSS) was used as control and IgGs were prepared by ammonium sulphate precipitation. ${ }^{31}$ The secondary antibody was the fluorescein isothiocyanate conjugated (FITC) pig anti-sheep Fab' previously described (pig-FITC). ${ }^{31}$

\section{IMMUNOLOCALISATION}

The MMPs and TIMPs are usually secreted in vivo in small amounts and are not stored intracellularly. To increase sensitivity in order to locate precisely the cellular source of these proteins, tissues were incubated with the ionophore monensin, which blocks translocation of secreted protein while allowing synthesis to continue. ${ }^{31} 37$ This procedure results in intracellular accumulation of antigen in the Golgi apparatus and secretory vesicles of cells, which can then more readily be localised by indirect immunofluorescence.

Frozen sections $(7 \mu \mathrm{m})$ were cut on a cryostat and taken onto glass slides. Sections were fixed ( $4 \%$ freshly prepared formaldehyde for 30 minutes), permeabilised $(0 \cdot 1 \%$ Triton $\mathrm{X}-100$ for five minutes) and incubated in 4-chloro-1-naphthol $(2 \cdot 8 \mathrm{mmol} / 1$ in methanol/ phosphate buffered saline (PBS) with $0.01 \%$ hydrogen peroxide for 12 minutes) to prevent non-specific binding of fluorescein to eosinophils. Sections were then incubated for 30 minutes at room temperature with IgG preparations of either antiserum or NSS (all 50 $\mu \mathrm{g} / \mathrm{ml}$ ). Twenty four sections were cut at each location in all samples, and the antibodies assigned to each set of eight (for example anticollagenase on Nos 2,10, and 18) to limit variation in tissue histology as far as possible. The sections were washed in PBS three times for five minutes after each of the above steps. They were then incubated for 30 minutes with the pig-FITC second antibody, washed, and counterstained with methyl green $1 \mathrm{mg} / \mathrm{ml}$ for two minutes to stain nuclei red.
All sections were mounted in Citifluor (University of Kent at Canterbury) and viewed by fluorescence microscopy on a Zeiss Photomicroscope III with epifluorescence and wide band FITC filter. Photographs were taken on Agfachrome 1000 RS film uprated during processing to 2000 ASA. Some sections were also analysed by confocal microscopy using a Biorad MRC 600 confocal microscope with a krypton/argon mixed gas laser; photographs were taken on Agfa APX 25 film from a colour monitor. Coverslips were then removed and the sections stained with Harris's haematoxylin and eosin, observed by bright field optics and photographed on Ektachrome 50 film.

\section{Results}

Synovia from seven patients with a history of rheumatoid arthritis (patients 1-7, table 1) and three patients with a history of osteoarthritis (patients 8-10) were examined immunohistochemically in detail using specific antisera to six MMPs and TIMP-1 and TIMP-2. The synovia showed a considerable range in histological appearance and MMP distributions (table 2 ). Stromelysin 1 was observed in all synovia, bound to extracellular matrix, within cells, or both, indicating stromelysin synthesis. Intracellular staining for stromelysin 1 , collagenase, gelatinase A, and TIMP-1 was focal, with marked regional variations, but in general the extent of staining correlated with the degree of synovial inflammation. Interesting observations from individual patients are described in detail below.

The synovial samples from patient 7 , with seronegative polyarthritis, were heavily infiltrated with inflammatory cells with a well defined lining layer three to five cells thick overlying fibrovascular tissue. When this tissue was cultured in monensin, sectioned, and stained with antisera to MMPs, extensive regions of the lining cells showed strong intracellular immunofluorescence for stromelysin (fig 1a), with immunofluorescence of the extracellular matrix (fig 1a). However, there were also regions where both lining cells and extra-

Table 2. Histology and distribution of MMPs and TIMPs in ex vivo synovia and those cultured for six hours with monensin to accumulate intracellular antigen ${ }^{31}{ }^{37}$

\begin{tabular}{|c|c|c|c|c|c|c|c|c|c|}
\hline Patient & Synovial histology & Coll. & $S L 1$ & $S L 2$ & Mat. & Gel. $A$ & Gel. B & TIMP-1 & TIMP-2 \\
\hline 1 & $\begin{array}{l}\text { Thin synovial lining, } \\
\text { little infiltrate }\end{array}$ & 0 & $\square \mathrm{L}+\mathrm{S}++$ & 0 & 0 & 0 & 0 & 0 & 0 \\
\hline 2 & $\begin{array}{l}\text { Heavily infiltrated } \\
\text { proliferative fronds }\end{array}$ & 0 & a +++ & 0 & 0 & $\square \mathrm{S}+$ & 0 & $\square S+$ & 0 \\
\hline 3 & $\begin{array}{l}\text { Heavily infiltrated synovial } \\
\text { fronds with cuffed blood vessels }\end{array}$ & 0 & $\mathbf{a}$ & 0 & 0 & 0 & 0 & 0 & 0 \\
\hline 4 & $\begin{array}{l}\text { Fibrovascular tissue with } \\
\text { foci of inflammatory cells }\end{array}$ & $S+$ & $\mathbf{s +}$ & 0 & 0 & 0 & 0 & $S+$ & 0 \\
\hline 5 & $\begin{array}{l}\text { Thin synovial lining with some } \\
\text { foci of inflammatory cells }\end{array}$ & 0 & $\square \mathrm{L}+$ & 0 & 0 & 0 & PMNL & 0 & 0 \\
\hline 6 & $\begin{array}{l}\text { Heavily infiltrated } \\
\text { synovial fronds }\end{array}$ & $\begin{array}{l}\mathrm{L}+++ \\
\mathrm{S}++\end{array}$ & $\underset{\mathrm{S}+++}{\mathrm{L}+++}$ & 0 & $\mathrm{~L}+++$ & $\mathrm{S}+++$ & 0 & $\begin{array}{l}\mathrm{L}+++ \\
\mathrm{S}+++\end{array}$ & 0 \\
\hline 7 & $\begin{array}{l}\text { Heavily infiltrated } \\
\text { synovial fronds }\end{array}$ & $\begin{array}{l}\mathrm{L}+++ \\
\mathrm{S}+++\end{array}$ & $\begin{array}{c}-\mathrm{L}+++ \\
\mathrm{S}++\end{array}$ & 0 & 0 & $\mathrm{~S}+++$ & 0 & $\begin{array}{l}\mathrm{L}+++ \\
\mathrm{S}+++\end{array}$ & 0 \\
\hline 8 & $\begin{array}{l}\text { Thin synovial lining } \\
\text { with little infiltrate }\end{array}$ & 0 & $\square \mathrm{L}+$ & 0 & 0 & 0 & 0 & 0 & 0 \\
\hline 9 & $\begin{array}{l}\text { Thin synovial lining with } \\
\text { little infiltrate }\end{array}$ & $S++$ & $\mathrm{S}+++$ & 0 & 0 & 0 & 0 & $S++$ & 0 \\
\hline 10 & $\begin{array}{l}\text { Thin synovial lining, a few } \\
\text { inflammatory cell foci }\end{array}$ & 0 & $\square S+$ & 0 & 0 & 0 & 0 & 0 & 0 \\
\hline
\end{tabular}

Coll. = Collagenase; SL1, SL2 = stromelysins 1 and 2; Mat. = matrilysin; Gel. A, Gel. B = gelatinases A and B; TIMP-1, TIMP$2=$ tissue inhibitors of metalloproteinases 1 and $2 ; \mathrm{L}=$ lining cells; $\mathrm{S}=$ stromal cells; $\mathrm{PMNL}=$ polymorphonuclear leucocytes. Immunofluorescence indicating antigen symthesis: $+=1-10$ positive cells per section $\ldots . .+++=>50$ positive cells. Connective tissue matrix staining: $\square=$ weak, small area ... .... ... = intense, extensive staining. 

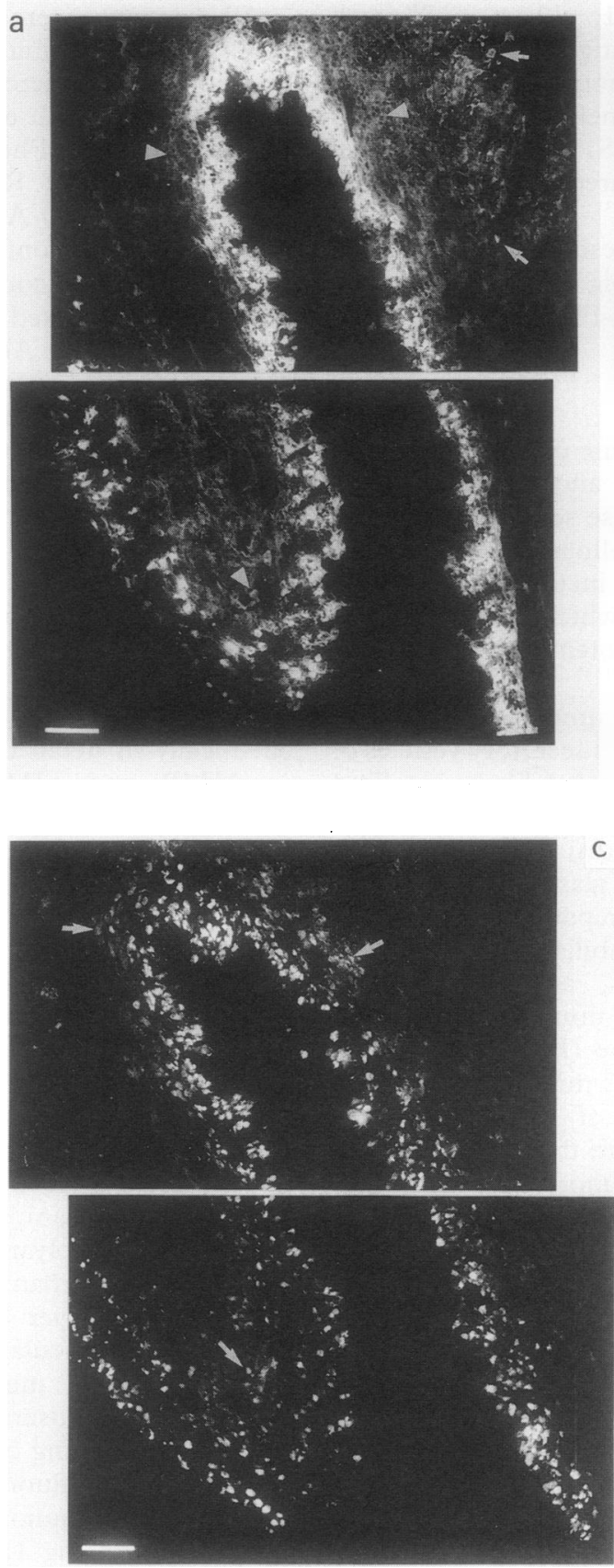

cellular matrix were negative. Adjacent sections stained with anti-collagenase also had intracellular immunofluorescence in the same lining cell regions where stromelysin was seen (fig 1b) and fibrovascular tissue below the synovial fronds contained many positive stromal cells, but there was no staining of extracellular matrix. Sections stained with antigelatinase $\mathbf{A}$ had no immunofluorescence of lining cells or matrix, but large numbers of stromal cells in the underlying connective tissue had weak intracellular immunofluorescence (fig 2a). Sections stained with anti-TIMP-1 showed strong immunofluorescence of lining cells and many underlying stromal cells (fig 1c), indicating more widespread cellular synthesis of TIMP-1 than of either of the enzymes. Sections of this synovium were negative for stromelysin 2, matrilysin, gelatinase B, and TIMP-2, and for the control NSS IgG.

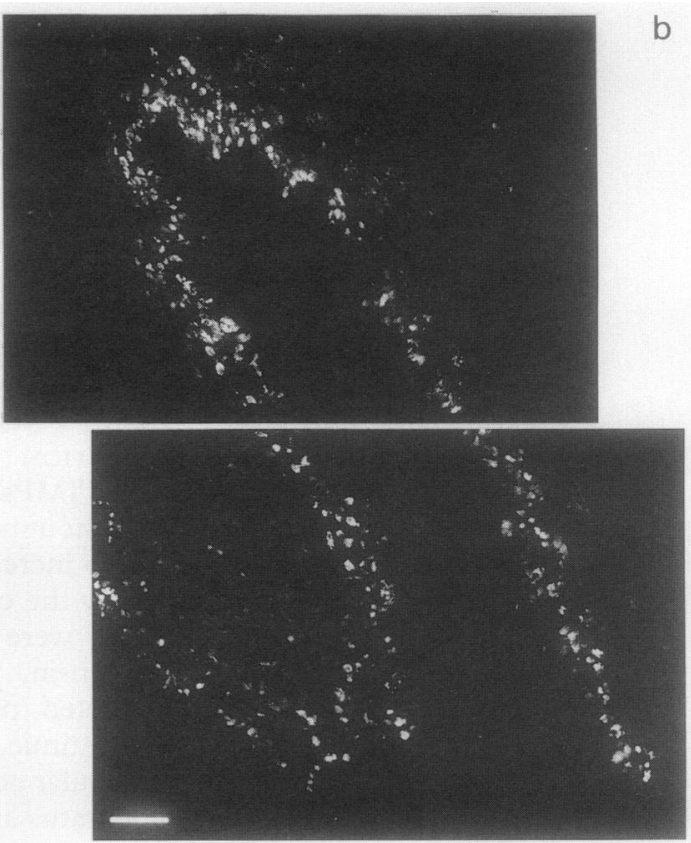

Figure 1 Distribution of stromelysin, collagenase and TIMP-1 in a rheumatoid synovium. Synovium from patient 7 was cultured in monensin, frozen, sectioned, and stained by indirect immunofluorescence with antibodies to (a) stromelysin, (b) collagenase and (c) TIMP-1. Sections were analysed on an MRC 600 confocal microscope using the $488 \mathrm{~nm}$ line, and data collected by Kalman averaging over 20 scans at slow scan speed, followed by normalising the image before photography. Bars $=100 \mu \mathrm{m}$. a: Anti stromelysin. Intense intracellular fluorescence is present in synovial lining cells, and in some stromal cells (arrows). The extracellular matrix below the lining is also strongly fluorescent, but there are no positive cells (arrow heads). b: Anti-collagenase. Synovial lining cells have strong intracellular immunofluorescence, with only a few stromal cells weakly positive. There is no matrix fluorescence. c: Anti-TIMP. Synovial lining cells and many underlying stromal cells (arrows) have intracellular fluorescence.

Synovium from patient 6 , the other subject with atypical seronegative rheumatoid arthritis, was also heavily infiltrated with inflammatory cells and, when stained with anti-stromelysin, showed strong immunofluorescence of extracellular matrix and cells (fig $2 b$ ). As the antistromelysin antiserum reacts with both stromelysins 1 and 2 (see Methods), adjacent sections were stained with either the rabbit or the sheep antisera to stromelysin 2 , and were found to be negative (fig 2c), indicating that the matrix and cellular immunofluorescence were attributable to stromelysin 1. However, sections of this tissue stained with antimatrilysin contained discrete areas of lining cells with intracellular fluorescence (fig 2d), indicating matrilysin synthesis. These areas frequently coincided with areas of bright stromelysin fluorescence. The distributions of collagenase, gelatinase A, and TIMP-1 were similar to those seen in patient 7 , with TIMP-1 

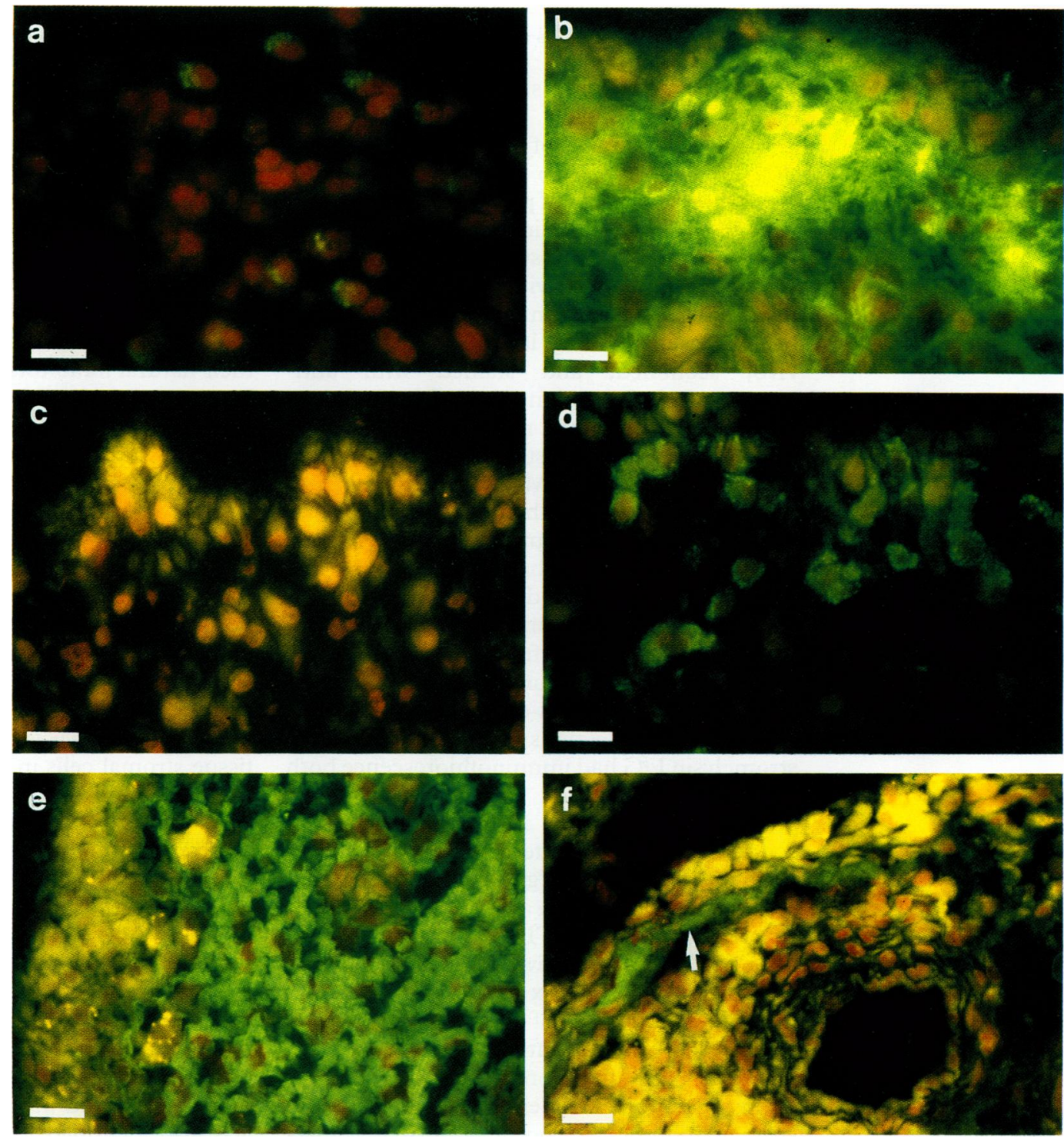

Figure 2 Immunolocalisation of gelatinase, stromelysin and matrilysin in rheumatoid synovia. Synovia from patients 7 $(a)$, and $6(b, c, d)$ were cultured in monensin before freezing. Synovium from patient $2(e, f)$ was frozen ex vivo. Tissues were sectioned and stained with anti-gelatinase $(a, f)$, anti-stromelysin $(b, e)$, sheep anti-stromelysin 2 (c) or antimatrilysin (d). Sections were observed by immunofluorescence microscopy. Nuclei are counterstained and appear red. Bars $=20 \mu \mathrm{m}$. a: Anti-gelatinase A. Some connective tissue cells have weak juxtanuclear green fluorescence indicating gelatinase A synthesis. B: Anti-stromelysin. Extracellular matrix of synovial lining and below is strongly fluorescent, indicating matrix-bound stromelysin, and some cells have vesicular intracellular fluorescence of stromelysin synthesised during the culture period. c: Anti-stromelysin 2. The identical region of the section adjacent to (b) had no green fluorescence, showing that the intracellular and extracellular staining in (b) represents stromelysin 1. d: Anti-matrilysin. Some synovial lining and sublining cells have intracellular immunofluorescence, indicating matrilysin synthesis. e: Antistromelysin. Synovium ex vivo has bright stromelysin immunofluorescence of connective tissue matrix. This intense and extensive matrix staining also occurred in patients 2, 3 and 6 and is represented by $\square$ in table 2. The lining cell layer is negative but contains cells with yellow autofluorescent granules, probably phagocytosed material. f: Anti-gelatinase A. The section adjacent to $(e)$ had a small area of matrix immunofluorescence immediately underlying the synovial lining (arrow), representing gelatinase $A$ bound to connective tissue components.

synthesising cells again more extensive and numerous than the MMPs.

The synovium removed from patient 1, with late stage quiescent rheumatoid arthritis, consisted of fibrovascular stroma without lymphocytic foci bordered by a lining layer one or two cells thick. Sections of tissue cultured in monensin then stained with the antiserum to stromelysin contained a few lining cells and some stromal cells with intracellular immunofluorescence, indicating stromelysin synthesis; a small area of extracellular matrix immediately below the lining layer also had immunofluorescence. Adjacent sections stained with either the rabbit or sheep antisera to stromelysin 2 were negative, indicating that the cells were synthesising stromelysin 1. Sections stained with the other antisera were negative, confirming the histological picture of a relatively inactive joint. Adjacent sections stained with NSS IgG as control were also negative. Ex vivo synovium from patient 5 , which also showed more advanced disease with secondary osteoarthritic changes, contained a few polymorphonuclear leucocytes with intracellular gelatinase B immunofluorescence within small inflammatory cell foci. Polymorphonuclear leucocytes were identified in other ex vivo synovia using the methyl green nuclear counterstain and confirmed histologically, but they were negative for gelatinase 
B, presumably having degranulated before tissue excision.

As the synovial samples cultured in monensin from all patients had some stromelysin staining of extracellular matrix, samples frozen ex vivo without culture were also examined. Areas of positive matrix (but no positive cells) were again observed in samples from all patients. The synovium from patient 2 was highly villous with many lymphocytic foci and perivascular inflammation, bordered by a thickened lining layer: when frozen ex vivo, sectioned, and stained with antistromelysin IgG, sections had bright immunofluorescence of stromal matrix throughout (fig 2e). Adjacent sections stained with NSS, anticollagenase, or anti-TIMP IgGs were negative, but sections stained with anti-gelatinase $A$ had positive matrix in one limited area only (fig $2 f$ ). These data indicate that stromelysin 1 and gelatinase A were bound to matrix in vivo, not as a result of the six hour period of culture with monensin. Sections from adjacent tissue cultured in monensin for six hours and stained with either NSS or anti-collagenase IgGs were negative, but sections stained with antistromelysin IgG had immunofluorescence both on collagenous matrix and within cells just below the lining layer, indicating stromelysin synthesis (not illustrated). Sections stained with anti-gelatinase A IgG had positive matrix only in one small region and a few positive cells (not illustrated). Anti-TIMP-1 stained sections also had a few positive stromal cells, and localised positive matrix mainly just below the lining layer in regions of cells with intracellular stromelysin (not illustrated).

As the immunofluorescence in the antistromelysin stained slides was so extensive and striking and does not occur in normal synovia (data not shown), ${ }^{18} 20$ the presence of stromelysin was cross checked by staining sections with an antiserum raised against active $\mathrm{N}$-terminal stromelysin isolated from rabbit bone culture media; this antiserum cross reacts with human stromelysin. ${ }^{38}$ Both the antihuman and the anti-rabbit stromelysin antisera immunolocalise both active high molecular mass and latent prostromelysin on collagen fibrils. ${ }^{30}$ The sections had both intracellular and matrix fluorescence, confirming the widespread distribution of stromelysin in this synovium. The experiments of Allan et $a l^{30}$ showed that this matrix bound enzyme could be either latent or active stromelysin, but also showed that TIMP-1 binds to matrix bound active stromelysin and not matrix bound prostromelysin. The immunolocalisation of TIMP-1 on matrix in the same region as stromelysin in this synovial sample suggests that at least a proportion of the stromelysin is in the active form. Sections stained with either the rabbit or sheep antisera to stromelysin 2 were negative, indicating that the matrix and cellular staining were attributable to stromelysin 1 .

Synovia from the three osteoarthritic joints (patients 8-10) were found to have a distribution of MMP similar to that in patient 1 with inactive rheumatoid arthritis (table 2).
All three had small areas of weak stromelysin 1 immunofluorescence on extracellular matrix in both ex vivo and cultured samples. The synovial lining cells were negative for collagenase in all samples, but one patient (patient 8 ) had a few lining cells positive for stromelysin.

\section{Discussion}

In this paper we have documented the frequencies and distributions of six MMPs and their natural inhibitors, TIMP-1 and TIMP-2, in seven rheumatoid and three osteoarthritic synovia. Stromelysin 1 was present in all synovia, in ex vivo tissue bound to extracellular matrix, within cells, or both, indicating stromelysin synthesis immediately following resection. The extent of staining varied both between samples and within each sample, but the most extensive matrix and cellular staining occurred in rheumatoid synovia. Stromelysin 2 was never observed, but intracellular matrilysin was seen in one active inflammatory synovium. Focal synthesis of collagenase was seen in lining cells of two synovia, and in connective tissue stromal cells in four synovia. Gelatinase A was observed in stromal cells from four synovia. TIMP-1 synthesis was observed in five synovia, and in two highly active synovia the distribution of TIMP-1 positive cells was more widespread than that of MMPs. No TIMP-2 was seen in any of the synovial samples.

To our knowledge this is the first report of the occurrence of stromelysin 1 bound to extracellular matrix components of synovia. It was present in ex vivo samples from both osteoarthritic and rheumatoid synovia, but was more widespread in the latter. Matrix staining was also identified in synovial samples which contained no stromelysin secreting cells (for example those from patient 3 ), suggesting that the stromelysin 1 may have been bound to the matrix for some time. Synthesis of stromelysin by synovial lining and stromal cells has been reported by other authors using both immunolocalisation ${ }^{12-15}$ and in situ hybridisation methods ${ }^{14} 1920$ and our data reinforce their observations that expression is focal and related to the degree of inflammation. In situ methods would not, however, detect enzymes already bound to extracellular matrix. The polyclonal antiserum used in this study recognises both the pro, active and C-terminal forms of stromelysin ${ }^{30}$ and all these forms bind to collagen via the C-terminal domain. ${ }^{30}$ Stromelysin has a broad spectrum of activity against many components of the connective tissue matrix ${ }^{4}$ and its presence on the matrix over prolonged periods may contribute to potentiation of the synovitis.

None of the synovia examined contained any stromelysin 2. Cultured rheumatoid synovial cells have been shown to express very low levels of stromelysin $2 \mathrm{mRNA},{ }^{22}$ but it is likely that the six hour period of culture in monensin used for this study was insufficient to detect very small concentrations of protein synthesis. As a positive control the antiserum to stromelysin 2 was shown to immunolocalise stromelysin 2 in 
NSO mouse myeloma cells transfected with stromelysin 2 (see Methods). However, matrilysin, another possible member of the stromelysin group, was identified in synovium from a patient with seronegative rheumatoid arthritis in a shoulder joint. Matrilysin was originally extracted from rat uterus, ${ }^{39}$ and has been shown to be a secreted product of developing human mononuclear phagocytes. ${ }^{40}$ This is the first report, to our knowledge, of expression of matrilysin by cells in synovium. While further work is necessary to confirm the cell type(s) secreting the matrilysin and to find further examples, it is possible that they are mononuclear phagocytes from the recent inflammatory infiltration.

Previous workers have identified collagenase in synovia by both immunolocalisation and in situ hybridisation ${ }^{11} 16-20$ and our results agree that collagenase may be expressed by both synovial lining and stromal cells with marked regional variations. Two rheumatoid synovia (patients 2 and 3) heavily infiltrated with inflammatory cells were found to be collagenase negative (table 2), suggesting that synthesis may be episodic as well as focal. These patients both showed active inflammatory changes in their synovium, but no significant evidence of articular cartilage erosion or degeneration. Focal synthesis of gelatinase A was observed in synovia from four patients (three rheumatoid, one osteoarthritic). It was frequently seen in connective tissue stromal cells away from the synovial surface, whereas collagenase and stromelysin were predominantly observed in the lining cells and stromal cells immediately below the lining. Focal synthesis of gelatinase A by stromal cells was also observed on days 7-28 after induction of arthritis in two rabbit models, ${ }^{41}$ suggesting that this enzyme has an important role in would healing. The localisation of gelatinase A to extracellular matrix is consistent with the findings of Murphy et $a l^{42}$ who showed that gelatinase $\mathrm{A}$ binds tightly to collagen through its fibronectin-like domain in addition to binding to cell membranes. Tetlow et $a l^{43}$ demonstrated synthesis of gelatinase $B$ by a few macrophages in some synovial tissue sections. In the samples we have examined we were unable to find any gelatinase B other than in polymorphonuclear leucocytes.

All patients studied had received a variety of drug treatments before removal of synovia. It is noteworthy, however, that patient 6 had received both systemic and intra-articular steroids for several months before removal of the synovial specimen, which showed marked hyperplasia, but there was still abundant cellular synthesis of MMPs and TIMP-1. McCachren reported that two patients who had received prednisone in low dosage for a long period of time had synovia with high scores for inflammation and collagenase and TIMP mRNAs, ${ }^{20}$ and a recent study found no lack of stromelysin mRNA expression in two patients who had been treated with steroids. ${ }^{21}$ However, Firestein $e t a l^{18}$ studied the effect of intra-articular corticosteroid injections on synovial tissue gene expression using serial synovial biopsies and found that collagenase and TIMP-1 mRNA, although abundant in pre-steroid samples, were nearly undetectable in post-steroid-injection tissues.

The finding of stromelysin 1 in all synovial samples from 10 patients with disparate clinical diagnoses and histories, in contrast to its absence from normal synovia (data not shown), ${ }^{18} 20$ clearly implicates this enzyme in the arthritic process. We have also shown that collagenase, gelatinase A, and matrilysin may have a role in the synovitis associated with rheumatoid arthritis, but are not a significant feature in osteoarthritic joints. However, marked regional variations were found in the synthesis of these MMPs, indicating that these diseases are episodic and that the control of enzyme synthesis is focal. This indicates the need for further work to colocalise MMP synthesis with cytokine expression in synovia from arthritic joints to explore the mechanisms which control the synthesis and degradation of extracellular matrix components in articular cartilage. A better understanding of the control of these processes may indicate ways to downregulate MMP overproduction without compromising normal tissue remodelling.

We thank the Medical Research Council (UK) for financial support, $\mathrm{Mr}$ Jim Reilly for technical assistance, and $\mathrm{Mr}$ Christopher Green for printing the colour photographs.

1 Harris E. Rheumatoid arthritis. Pathophysiology and implications for therapy. $N$ Engl $f$ Med 1990; 322: 1277-89.

2 Krane S M, Conca W, Stephenson M L, Amento E P, Goldring $M$ B. Mechanisms of matrix degradation in rheumatoid arthritis. Ann NY Acad Sci 1990; 580: 340-54.

3 Barrett A J, Saklatvala J. Proteinases in joint disease. In: Kelley W N, Harris E D, Ruddy S, Sledge B, eds. Textbook of rheumatology, vol 1. Philadelphia: WB Saunders, 1985; 182-92.

4 Murphy G, Reynolds J J. Extracellular matrix degradation. In: Royce P M, Steinmann B, eds. Connective tissue and its heritable disorders. New York: Wiley-Liss Inc, 1993: 287-316.

5 Krane S M. Collagenase production by human synovial tissues. Ann NY Acad Sci 1975; 256: 289-303.

6 McGuire M B, Murphy G, Reynolds J J, Russell R G G. Production of collagenase and inhibitor (TIMP) by normal, rheumatoid and osteoarthritic synovium in vitro: effects of hydrocortisone and indomethacin. Clin Sci 1981; 61: 703-10.

7 Murphy G, McGuire M B, Russell R G G, Reynolds J J. Characterization of collagenase, other metalloproteinases and an inhibitor (TIMP) produced by human synovium and cartilage in culture. Clin Sci 1981; 61: 711-6.

8 Martel-Pelletier J, Cloutier J-M, Pelletier J-P. In vivo effects of antirheumatic drugs on neutral collagenolytic proteases in human rheumatoid arthritis cartilage and synovium. f Rheumatol 1988; 15: 1198-1204.

9 Dayer J-M, Krane S M, Russell R G G, Robinson D R. Production of collagenase and prostaglandins by isolated adherent rheumatoid synovial cells. Proc Nat Acad Sci USA 1976; 73: 945-9.

10 Woolley D E, Harris E D, Mainardi C L, Brinckerhoff C E. Collagenase immunolocalization in cultures of rheumatoid synovial cells. Science 1978; 200: 773-5.

11 Woolley D E, Crossley M J, Evanson J M. Collagenase at sites of cartilage erosion in the rheumatoid joint. Arthritis Rheum 1977; 20: 1231-9.

12 Okada Y, Takeuchi N, Tomita K, Nakanishi I, Nagase H. Immunolocalisation of matrix metalloproteinase 3 (stromelysin) in rheumatoid synovioblasts (B cells): correlation with rheumatoid arthritis. Ann Rheum Dis 1989; 48: 645-53.

13 Case J P, Lafyatis R, Remmers E F, Kumkumian G K, Wilder $R \quad L$. Transin/stromelysin expression in rheumatoid synovium. A transformation-associated metalloproteinase secreted by phenotypically invasive synoviocytes. Am f Pathol 1989; 135: 1055-64

14 Sawai T, Murakami K, Ohtani Y, Kurkinnen M, Kyogoku M, Hayashi $M$. Stromelysin synthesizing cells in the synovial tissues of rheumatoid arthritis demonstrated methods. Tohoku f Exp Med 1990; 160: 285-6. 
15 Okada Y, Shinmei M, Tanaka O, et al. Localization of matrix metalloproteinase 3 (stromelysin) in osteoarthritic cartilage and synovium. Lab Invest 1992; 66: 680-90.

16 Okada Y, Gonoji Y, Nakanishi I, Nagase H, Hayakawa T. Immunohistochemical demonstration of collagenase and tissue inhibitor of metalloproteinases (TIMP) in synovia lining cells of rheumatoid synovium. Virchows Archiv B Cell Pathol 1990; 59: 305-12.

17 McCachren S S, Haynes B F, Niedel J E. Localization of collagenase mRNA in rheumatoid arthritis synovium by in situ hybridization histochemistry. 7 Clin Immunol 1990 10: $19-27$.

18 Firestein G S, Paine M M, Littman B H. Gene expression (collagenase, tissue inhibitor of metalloproteinases, complement, and HLA-DR) in rheumatoid arthritis and osteoarthritis synovium. Quantitative analysis and effect osteoarthritis synovium. Quantitative analysis and effect
of intraarticular corticosteroids. Arthritis Rheum 1991; 34:

19 Gravallese E M, Darling J M, Ladd A L, Katz J N, Glimcher L H. In situ hybridization studies of stromelysin and collagenase messenger RNA expression in rheumatoid synovium. Arthritis Rheum 1991; 34: 1076-84.

$20 \mathrm{McCachren}$ S S. Expression of metalloproteinases and metalloproteinase inhibitor in human arthritic synovium. Arthritis Rheum 1991; 34: 1085-92.

21 Wolfe G C, MacNaul K L, Buechel F F, et al. Differential in vivo expression of collagenase messenger RNA in synovium and cartilage. Quantitative comparison with synovium and cartilage. Quantitative comparison with stromelysin messenger RNA levels in human rheumatoid arthritis and osteoarthritis patients and in two animal models of acute in

22 Sirum K L, Brinckerhoff C E. Cloning of the genes for human stromelysin and stromelysin 2: differential expression in rheumatoid synovial fibroblasts. Biochemistry 1989; 28: 8691-8.

23 Cawston T E, Mercer E, De Silva M, Hazleman B L. Metalloproteinases and collagenase inhibitors in rheumatoid synovial fluid. Arthritis Rheum 1984; 27: 285-90.

24. Walakovits L A, Moore V L, Bhardwaj N, Gallick G S, Lark M W. Detection of stromelysin and collagenase in synovial fluid from patients with rheumatoid arthritis and synovial fluid from patients with rheumatoid arthritis and posttra

25 Clark I M, Powell L K, Ramsey S, Hazleman B L, Cawston T E. The measurement of collagenase, tissue inhibitor of metalloproteinases (TIMP), and collagenaseTIMP complex in synovial fluids from patients with osteoarthritis and rheumatoid arthritis. Arthritis Rheum 1993; 36: 372-9.

26 Lohmander L S, Hoerrner L A, Lark M W. Metalloproteinases, tissue inhibitor, and proteoglycan fragments in knee synovial fluid in human osteoarthritis. Arthritis Rheum 1993; 36: 181-9.

27 Mercer E, Cawston T E, De Silva M, Hazleman B L. Purification of a metalloproteinase inhibitor from human Purification of a metalloproteinase inhibitor from human

28 Hipps D S, Hembry R M, Docherty A J P, Reynolds J J Murphy G. Purification and characterisation of human $72-\mathrm{kDa}$ gelatinase (type IV) collagenase. Use of immunolocalisation to demonstrate the non-coordinated regulation of the $72-\mathrm{kDa}$ and $95-\mathrm{kDa}$ gelatinases by human fibroblasts. Biol Chem Hoppe-Seyler 1991; 372: 287-96.

29 Murphy G, Ward R, Hembry R M, Reynolds J J, Kuhn K, Tryggvason $\mathrm{K}$. Characterization of gelatinase from pig polymorphonuclear leucocytes. A metalloproteinase 258: 463-72.

30 Allan J A, Hembry R M, Angal S, Reynolds J J, Murphy G. Binding of latent and high $M_{\mathrm{r}}$ active forms of stromelysin to collagen is mediated by the C-terminal domain. $7 \mathrm{Cell}$ Sci 1991; 99: 789-95.

31 Hembry R M, Murphy G, Reynolds J J. Immunolocalization of tissue inhibitor of metalloproteinases (TIMP) in human cells. Characterization and use of a specific antiserum. F Cell Sci 1985; 73: 105-19.

32 Ward R V, Hembry R M, Reynolds J J, Murphy G. The purification of tissue inhibitor of metalloproteinases-2 from its $72 \mathrm{kD}$ progelatinase complex. Demoteinases- 2 a progela the biochemical similarities of tissue inhibitor of metalloproteinases-2 and tissue inhibitor

33 Whitham S E, Murphy G, Angel P, et al. Comparison of human stromelysin and collagenase by cloning and sequence analysis. Biochem f 1986; 240: 913-6.

34 Murphy G, Cockett M I, Ward R V, Docherty A J P. Matrix metalloproteinase degradation of elastin, type IV collagen and proteoglycan. A quantitative comparison of the activities of $95 \mathrm{kDA}$ and $72 \mathrm{kDA}$ gelatinases, stromelysins-1 and -2 and punctuated metalloproteinase (PUMP). Biochem f 1991; 277: 277-9.

35 Murphy G, Allan J A, Willenbrock F, Cockett $M$ I, O'Connell J P, Docherty A J P. The role of the C-terminal domain in collagenase and stromelysin specificity. $7 \mathrm{Biol}$ Chem 1992; 267: 9612-8.

36 Murphy G, Willenbrock $F$, Ward $R$ V, Cockett $M$ Eaton D, Docherty A J P. The C-terminal domain of $72 \mathrm{kDa}$ gelatinase A is not required for catalysis, but is essential for membrane activation and modulate interactions with tissue inhibitors of metalloproteinases. Biochem f 1992; 283: 637-41.

37 Nagase H, Brinckerhoff C E, Vater C A, Harris E D. Biosynthesis and secretion of procollagenase by rabbit synovial fibroblasts. Inhibition of procollagenase secretion by monensin and evidence for glycosylation of procollagenase. Biochem 7 1983; 214: 281-8.

38 Murphy G, Hembry R M, Reynolds J J. Characterization of a specific antiserum to rabbit stromelysin and of a specific antiserum to rabbit stromelysin and demonstration of the synthesis of collagenase and Collagen Rel Res 1986; 6: 351 -64

39 Woessner J F, Taplin C J. Purification and properties of small latent matrix metalloproteinase of the rat uterus. f Biol Chem 1988; 263: 16918-25.

40 Busiek D F, Ross F P, McDonnell S, Murphy G, Matrisian L M, Welgus H G. The matrix metalloproteinase matrilysin (PUMP) is expressed in developin human mononuclear phagocytes. 7 Biol Chem 1992; 267: 9087-92.

41 Hembry R M, Bagga M R, Murphy G, Henderson B, Reynolds J J. Rabbit models of arthritis: immunoarthritis: immunoinhibitor of metalloproteinase in synovium and cartilage. Am ₹ Pathol 1993; 143: 628-42.

42 Murphy G Nouyen Q Cockett M I, et al. Assessment of the role of the fibronectin-like domain of gelatinase A by analysis of a deletion mutant. 7 Biol Chem 1994; 269. 6632-6.

, Lees M, Ogata Y, Nagase H, Woolley D E. Differential expression of gelatinase B (MMP9) and stromelysin-1 (MMP-3) by rheumatoid synovial cells in vitro and in vivo. Rheumatol Int 1993; 13: 53-9. 